\title{
Surgical Outcome of Vesico-Vaginal Fistula (VVF) after Repair: Experience of 51 Cases in a Teaching Hospital of Dhaka City
}

\author{
Shimul Akter ${ }^{1}$, Fouzia Mujib², Mohammed Masudur Rahman ${ }^{3}$, Dewan Shahida Banu', \\ Taslima Begum ${ }^{5}$, Tahmida Firdousi ${ }^{6}$, Dipika Rani Mondal ${ }^{7}$ \\ ${ }^{1}$ Assistant Professor, Department of Gynaecology and Obstetrics, Monowara Sikder Medical College, Shariatpur, Bangladesh; \\ ${ }^{2}$ Assistant Professor, Department of Radiology \& Imaging, Dhaka Dental College, Dhaka, Bangladesh; ${ }^{3}$ Assistant Professor, \\ Sir Salimullah Medical College and Mitford Hospital, Dhaka, Bangladesh; ${ }^{4}$ Assistant Professor, Department of \\ Gynaecology \& Obstetrics, Shaheed Taj Uddin Ahmad Medical College, Gazipur, Bangladesh; ${ }^{5}$ Junior Lecturer, \\ Medical Assistant Training School (MATS), Sirajgonj, Bangladesh; ${ }^{6}$ Assistant Professor, Department of \\ Gynaecology \& Obstetrics, Dhaka Medical College, Dhaka, Bangladesh; ${ }^{7}$ Assistant Professor, Department of \\ Gynaecology \& Obstetrics, Khulna Medical College, Khulna, Bangladesh
}

[Received: 1 October 2018; Accepted: 12 November 2018; Published: 1 January 2019]

\begin{abstract}
Background: Surgical management of vesico-vaginal fistula is very crucial regarding the outcomes among the women. Objectives: The purpose of the present study was to see the surgical outcomes of vesico-vaginal fistula. Methodology: This cross-sectional study was carried out from July 2013 to December 2013 for a period of 6 months in the National Fistula Centre in the Department of Obstetrics \& Gynaecology at Dhaka Medical College Hospital (DMCH), Dhaka, Bangladesh. All patients who underwent surgical repair for iatrogenic VVF in National Fistula Centre of the department of Obstetrics and Gynaecology of Dhaka Medical College Hospital were included in this study. Patients who got themselves admitted to Obstetrics \& Gynaecology department of DMCH with the complaints of fistula. An interview usually lasted for an hour. The entire selected patients were interviewed for detailed history. Thorough physical examination was done. The surgical outcomes were recorded among the women. Result: A total number of 51 cases of VVF were recruited for this study. The mean age was $46.02( \pm$ SD 6.104$)$ years. Regarding the causes of iatrogenic vesico-vaginal fistula most of the cases $(88.2 \%)$ were abdominal hysterectomy. In $4(7.8 \%)$ patients lower segment caesarean section caused the situation. Vaginal hysterectomy was responsible for $3.9 \%(2 / 51)$ cases of iatrogenic VVF. In more than $90 \%$ cases (46/51) the surgical outcome was successful; while in 5 patients' fistula recurred 5 to 7 days following surgery. They were treated by re-operation later on. Conclusion: In conclusion abdominal hysterectomy is the most common cause of iatrogenic vesico-vaginal fistula with a very good surgical outcomes. [Journal of National Institute of Neurosciences Bangladesh, 2019;5(1): 29-32]
\end{abstract}

Keywords: Surgical outcome; vesico-vaginal fistula; VVF; iatrogenic

Correspondence: Dr. Shimul Akter, Assistant Professor, Department of Gynaecology and Obstetrics, Monowara Sikder Medical College, Shariatpur, Bangladesh; Email: shimulakter1072@gmail.com; Cell no.: +8801927643367

Conflict of interest: There is no conflict of interest relevant to this paper to disclose.

Funding agency: This research project was not funded by any group or any institution.

Contribution to authors: Akter S, Mujib F, Rahman MM contributed from the protocol preparation, data collection up to report writing. Manuscript writing was performed by Akter S. Statistical analysis was performed by Akter S, Banu DS. Begum T, Firdousi T, Mondal DR involved in revision of manuscript.

How to cite this article: Akter S, Mujib F, Rahman MM, Banu DS, Begum T, Firdousi T, Mondal DR. Surgical Outcome of Vesico-Vaginal Fistula (VVF) after Repair: Experience of 51 Cases in a Teaching Hospital of Dhaka City. J Natl Inst Neurosci Bangladesh, 2019;5(1): 29-32

Copyright: $@ 2019$. Akter et al. Published by Journal of National Institute of Neurosciences Bangladesh. This article is published under the Creative Commons CC BY-NC License (https://creativecommons.org/licenses/by-nc/4.0/). This license permits use, distribution and reproduction in any medium, provided the original work is properly cited, and is not used for commercial purposes.

\section{Introduction}

Genitourinary fistulas represent significant morbidity, especially in developing nations where obstetric trauma is the major etiologic cause ${ }^{1}$. The true incidence is unknown, and lack of seeking care is a major contribution for this uncertainty ${ }^{2}$. Vesicovaginal fistulas
(VVFs) are the most commonly acquired fistulae of the urinary tract. In developed nations, surgery, especially gynecologic procedures, is the major cause $\mathrm{e}^{3}$. The most common symptom in patients with VVF is constant urine leakage from the vagina. Predisposing factors such as chronic illnesses, previous surgery, chemotherapy, 
infections for postoperative fistulae are blamed, but the majority occur without any of these factors ${ }^{4}$.

In the last few decades, VVF have been dealt with quite successfully with various rather less invasive techniques like laparoscopic and robotic repairs, transurethral repair and laser welding ${ }^{1}$. However, these techniques have their own limitations. The ultimate aim of treatment with all the options of treatment is to restore the normal anatomy and to get rid of continuous dribbling of urine.

The type of surgical technique chosen (transvesical, transvaginal, laparoscopic or robotic), depends on surgeon experience, whether the fistula is simple or complex, and patient characteristics ${ }^{5}$. Complex or high fistulas are better treated abdominally with meticulous dissection, and simple ones can be treated easily vaginally by simple excision of the devascularized tissue and multi-layer approximation of healthy tissues ${ }^{6}$. Vaginal operations can be performed according to the Latzko technique as denuding vaginal epithelium and tension free re-suturing, without excision of the entire fistula tract. Thus the purpose of the present study was to see the surgical outcomes of vesico-vaginal fistula.

\section{Methodology}

This present study was designed as descriptive cross-sectional study. This study was carried out from July 2013 to December 2013 for a period of 6 months. The study place was National Fistula Centre in the Department of Obstetrics \& Gynaecology at Dhaka Medical College Hospital (DMCH), Dhaka, Bangladesh. All patients who underwent surgical repair for iatrogenic VVF in National Fistula Centre of the department of Obstetrics and Gynaecology of Dhaka Medical College Hospital were included in this study. Patients who got themselves admitted to Obstetrics \& Gynaecology department of DMCH with the complaints of fistula. Women with stress incontinence and rectovaginal fistula, patients with severe co-morbidity or those patients who were unwilling to cooperate. Purposive non-probability sampling technique was used. A semi structured questionnaire was prepared after pre-testing containing patient profile. This was used for collection of information by interviewing \& examining patients \& their reports. Data were collected for six months. An interview usually lasted for an hour. The entire selected patients were interviewed for detailed history. Thorough physical examination was done \& relevant lab investigations were arranged. Prior to the commencement of the study, the protocol was approved by the local research approval committee. Ethical clearance was obtained from ethical committee existent in DMCH. The aims \& objectives of the study was explained to respondents \& then informed \& verbal consent was taken from each subject. They were assured that all information \& records would be kept confidential and be used for research purpose only. All the data were checked and edited after collection. Data were then entered into computer, with the help of SPSS for Windows (IBM SPSS Statistics for Windows, version 19.0, Armonk, NY, IBM Corp.) An analysis plan was developed keeping in view with the objectives of the study.

\section{Results}

A total number of 51 cases of VVF were recruited for this study who were fulfilled the inclusion and exclusion criteria. The leading age group was 41-50 years $(70.6 \%)$. The second leading age group was 51-60 years with more than $15 \%$ patients. About $12 \%$ patients were relatively younger ( $\leq 40$ years). The age range was $38-70$ years. The mean age was $46.02( \pm \mathrm{SD}$ $6.104)$ years (Table 1).

Table 1: Distribution of the patients by age group

\begin{tabular}{lcc}
\hline Age Group & Frequency & Percent \\
\hline$\leq 40$ Years & 6 & 11.7 \\
41 to 50 Years & 36 & 70.6 \\
51 to 60 Years & 8 & 15.7 \\
$>60$ Years & 1 & 2.0 \\
Total & $\mathbf{5 1}$ & $\mathbf{1 0 0 . 0}$ \\
\hline
\end{tabular}

Causes of iatrogenic vesico-vaginal fistula are recorded. In most of the cases (88.2\%) abdominal hysterectomy was the cause of such fistula. In $4(7.8 \%)$ patients lower segment caesarean section caused the situation. Vaginal hysterectomy was responsible for $3.9 \%(2 / 51)$ cases of iatrogenic VVF (Table 2).

Table 2: Offending Surgeries to Causes Iatrogenic Vesico-Vaginal Fistula

\begin{tabular}{lcc}
\hline Causes of Iatrogenic VVF & Frequency & Percent \\
\hline Abdominal hysterectomy & 45 & 88.2 \\
LSCS & 4 & 7.8 \\
Vaginal hysterectomy & 2 & 3.9 \\
Total & $\mathbf{5 1}$ & $\mathbf{1 0 0 . 0}$ \\
\hline
\end{tabular}

LSCS=Lower segment caesarean section

Overall surgical outcome was recorded among the study population. In more than $90 \%$ cases $(46 / 51)$ the surgical outcome was successful; while in 5 patients' fistula recurred 5 to 7 days following surgery. They were treated by re-operation later on (Table 3). 
Table 3: Distribution of the patients by overall surgical outcome

\begin{tabular}{lcc}
\hline Surgical Outcome & Frequency & Percent \\
\hline Successful & 46 & 90.2 \\
Failed & 5 & 9.8 \\
Total & $\mathbf{5 1}$ & $\mathbf{1 0 0 . 0}$ \\
\hline
\end{tabular}

\section{Discussion}

VVF can be treated with surgery or conservatively and the timing of repair remains controversial ${ }^{1}$. According to the literature, it is apparent that there is no consensus as to the definition of late (2-4 months) and early (1 to 3 months) repair ${ }^{7}$. Conservative approaches such as catheter drainage, occlusion with fibrin, peeling of the tract epithelium with metal screw and steroid use have been reported in the literature for closure of small fistulas and outcome varies ${ }^{8}$.

In the current study a total of 51 cases were analyzed in the study. The mean age was $46.02( \pm$ SD 6.104$)$ years. Most of the respondents were illiterate $(55 \%)$ and one-third patients had primary level education. This socio-demographic scenario is almost identical to other study in developing countries ${ }^{9-11}$. One study in Turkey reported the mean patient age as $43\left( \pm\right.$ SD 3.86) years ${ }^{12}$. The alarming part is that majority of the cases occurred in middle age group and if not treated these women would have to spend a long part of their lives with this affliction, creating social and psychological problems in addition to medical issues.

In the developed countries, gynaecological procedures are considered to be responsible for most of the iatrogenic VVF cases ${ }^{4}$. In this present study, for more than $88 \%$ of the cases abdominal hysterectomy was the cause of such iatrogenic fistula. In 4(7.8\%) patients lower segment caesarean section caused the situation. Vaginal hysterectomy was responsible for 3.9\% (2/51) cases of iatrogenic VVF. These findings are quite comparable with the findings of an international study ${ }^{13}$. Majority of the patients who came to DMCH had been operated in private hospitals in the periphery and some had even been operated in small towns. The development of VVF in the post-hysterectomy cases indicates that they had been operated upon, either by inexperienced surgeons or surgeons who lacked proper training in this field.

There is a general agreement that when inadvertent injury to the bladder or ureter is detected during surgery, immediate on-table repair is the optimal treatment11. In contrast, when diagnosis is delayed, some prefer an immediate repair while others prefer repair to be delayed ${ }^{14}$. The classic procedure is to delay repair for several months, preferably 3 to 6 , and then to attempt a definitive repair ${ }^{15}$. This is the policy we had to adopt because patients did report to $\mathrm{DMCH}$ after a considerable time had elapsed. This delay, however, gives the damaged tissue a so-called 'maturation factor' permitting edema to subside, fibrosis to delineate, and inflammatory elements to disappear ${ }^{12}$. Though recently, there has been a tendency towards early repair within 4 to 6 weeks of injury ${ }^{11}$.

The commonest site of VVF is at the vaginal vault in the posterior bladder wall, as this is the usual site of bladder injury during abdominal hysterectomy ${ }^{15}$. This is the situation in the present study as well. Hysterectomy-induced fistulae are essentially due to a clean surgical wound with no extensive inflammation or tissue loss, which leads to a small fistula ${ }^{13}$. Definitive repair of VVF in the patients was performed at least 12 weeks after the offending surgery. No VVF repair performed through abdominal route failed. This could be explained by the fact that iatrogenic fistula is usually small, high-up in position and abdominal transvesical approach provides wider and comfortable exposure for easy and clean dissection and repair of bladder and vaginal wall. Out of 39 VVF repaired trans-vaginally, 5 failed first operations. They were managed subsequently by re-operation. The overall success rate of the VVF repair in the patients included in this study was $90.2 \%$ which is comparable to some international studies ${ }^{15}$.

\section{Conclusion}

In conclusion abdominal hysterectomy is the most common cause of iatrogenic vesico-vaginal fistula followed by lower segment caesarean section and vaginal hysterectomy. Regarding surgical outcomes majority are successfully repaired. A large scale study should be conducted in a multicenter basis to get real picture of the VVF repair among the women.

\section{References}

1. Tatar B, Oksay T, Cebe FS, Soyupek S, Erdemoğlu E. Management of vesico-vaginal fistulas after gynecologic surgery. Turkish journal of obstetrics and gynecology 2017;14(1):45.

2. Wall LL. Obstetric vesicovaginal fistula as an international public-health problem. Lancet 2006;368:1201-9

3. Eilber KS, Kavaler E, Rodriguez LV, Rosenblum N, Raz S. Ten-year experience with transvaginal vesicovaginal fistula repair using tissue interposition. J Urol 2003;169:1033-6

4. Raassen TJ, Ngongo CJ, Mahendeka MM. Iatrogenic genitourinary fistula: an 18-year retrospective review of 805 injuries. Int Urogynecol J 2014;25:1699-706

5. Fouad LS, Chen AH, Santoni CJ, Wehbe C, Pettit PD. Revisiting Conservative Management of Vesico-vaginal Fistula. J Minim Invasive Gynecol; 2016 
6. Gedik A, Deliktas H, Celik N, Kayan D, Bircan MK. Which Surgical Technique Should be Preferred to Repair Benign, Primary Vesicovaginal Fistulas? Urology J 2015;12:2422-7

7. Walsh K, Stone AR. How is the lower urinary tract affected by gynecological surgery? BJU Int. 2004; 94: 272-75

8. Sadiq G, Sadiq M, Sultana N. Obstetric trauma is the commonest cause of urogenital fistulae Rawal Med J 2008; 33: 197-200.

9. Shaikh AR, Shaikh S, Shaikh SN, Shaikh AH, Memon AA, Shaikh NA, Shaikh AF. Repair of vesico-vaginal fistula (Abdominal versus vaginal route). Professional Med J 2011; 18: 354-360

10. Rashid Y, Majeed T, Naeem M et al. Iatrogenic vesicovaginal fistula. JCPS 2010; 20: 436-438
11. Shafqat T, Faiz NR, Haleemi M. Profile and repair success of vesicovaginal fistula repair NWFP. JPMI 2009; 23:99-101.

12. Malik MA, Iqbal Z. Vesicovaginal fistulae: etiology and management at Allied Hospital, Faisalabad. Pak J Surg 2005;21:93-6.

13. Sachdev PS. Surgical repair of vesicovaginal fistula. J Coll Physicians Surg Pak 2002; 12:223-6

14. Blandy JP, Badenoch DF, Fowler CG, Jenkins BJ, Thomas NW. Early repair of iatrogenic injury to the ureter or bladder after gynecological surgery. The Journal of urology. 1991;146(3):761-5. 15. Eilber KS, Kavaler E, Rodriguez LV, Rosenblum N, Raz S. Ten-year experience with transvaginal fistula repair using tissue interposition. J Urol; 2003;169: 1033 